\title{
Synthesis and Characterization of Photocrosslinked Biobased Polyester Membrane
}

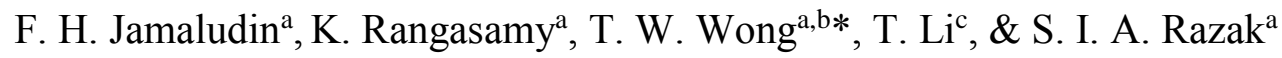

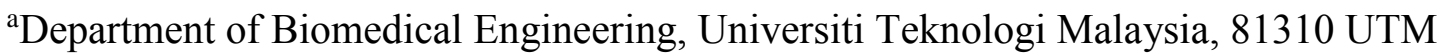 \\ Johor Bahru, Johor, Malaysia \\ ${ }^{\mathrm{b}}$ Faculty of Engineering, Universiti Teknologi Malaysia, 81310 UTM Johor Bahru, \\ Johor, Malaysia \\ 'Department of Engineering Mechanics, Zhejiang University, Hangzhou 310027 , \\ China
}

Submitted: 26/12/2018. Revised edition: 15/3/2019. Accepted: 17/3/2019. Available online: 15/7/2019

\begin{abstract}
A series of bio-based photocrosslinked polyester membranes, poly(1,8-octanediol-itaconatecitrate-dodecandioate), (POSCI) were synthesized through polycondensation followed by photocrosslinking under UV irradiation in the presence of 2,2-dimethoxy-2phenylacetophenone (DMPA) as photoinitiator (PI). Upon varied UV exposure time and DMPA content, the corresponding changes in chemical, structural, and mechanical properties of the polymer were studied. The transmission peak of FTIR spectrum centred at $1725 \mathrm{~cm}^{-1}$ indicates the formation of ester structure. Contact angle results suggested all of the synthesized POSCI membranes had hydrophilic properties as their contact angle is less than $90^{\circ}$. Sol-gel analysis shows that the swelling ratio of POSCI decreases while the gel fraction increases with increasing in photocrosslinking time. The tensile strength of POSCI, thus, increased correspondingly with longer UV exposure. Excess DMPA, however, proved otherwise.
\end{abstract}

Keywords: Bio-based membrane, polyester, photocrosslinked, ultraviolet

\subsection{INTRODUCTION}

Fossil resources such as coal, gas and oil are predicted to deplete by 2050 , if these non-renewable resources will further be used with the current consumption rates [1]. For this purpose, replacement of petroleum-based polymeric materials by bio-based polymers has gained growing attention in both industry and academia research [2]. Polymer materials play vital role in people's daily life and the amount of consumption has already exceeded steel [3]. However, most of these polymer materials are highly dependent on fossil resources. Replacing fossil raw materials with renewable alternatives is not only become a solution for depleting fossil resources but it also has been considered as a better solution for many environmental problems. This is due to the fact that, the use of fossil resources causes worldwide environmental problems and also increases carbon dioxide concentrations in the atmosphere [2].

Biobased polymers are polymers that are derived entirely or mostly from biomass, renewable resources [4]. With the global consumption expected to reach one million tonne by 2017 , the demand for renewable, biobased polymers is growing at $19 \%$ annually 
[4]. Alternatively, extensive studies has been conducted to utilise renewable resources for non-feed purposes owing to the sustainability of the agriculture industry of the future which would be more economic in the long run $[5,6]$.

Besides biobased polymers, environmentally friendly curing process also plays an essential part in environmental concerning issues [1]. The curing process here refer to UV curing method which is one of the photocuring process. UV curing has the potential to yield high-performance coating with high productivity rate, low energy consumption and extremely low volatile organic compounds (VOC) emissions [1].

One of the most common bio-based polymer is Poly(lactic acid) (PLA), a thermoplastic bio-based polymer (BBP), initially produced from sour milk in 1780 and commercially manufactured in 1881 [7, 8]. PLA has been widely used in the medical field for production of sutures, dental implants, stents, bone screws, pins and vascular grafts $[9,10]$. However, the thermoplastic PLA lacks in mechanical properties such as toughness, elongation at break, and impact strength besides requires processing temperatures higher than $185-190{ }^{\circ} \mathrm{C}$ [7]. In fact, heterogenous degradation, nonlinear mechanical strength loss, and instability of 3D geometry during hydrolysis of thermoplastics makes thermosetting counterpart a favourable option [11-13].

Therefore, since the past decade, researchers have been interested in developing thermosetting BBP through thermal crosslinking from bio-based polyesters which are hydrolysable for biodegradation [14]. Poly(glycerol sebacate) (PGS) [14] and poly(octanediol citrate) (POC) [15] are two novel thermosetting bio-based polyesters. However, thermosetting polyesters requires time-inefficient thermal crosslinking process with postpolymerisation heating duration of 7 hours [16] to 2 weeks [15] at $120^{\circ} \mathrm{C}$ temperature. On the contrary, a faster approach to produce crosslinked polymers is through photo-induced crosslinking [17]. Photocrosslinking is the process whereby free radical polymerization or cationic polymerization are initiated by ultraviolet (UV) or visible light irradiation to form chemical crosslinks at the crosslinking sites producing photosets. This crosslinking process could take as short as few seconds [18] to 10 minutes $[13,19]$. Recently, photocrosslinking systems are predominantly used in adhesives, ink and coating to enhance surface properties in high-technology areas including automotive, electric, and electronic devices [20].

In this present work, a photocrosslinked bio-based polyester membrane was synthesized through polycondensation of 1,8-octanediol, itaconic acid, succinic acid and citric acid with 2,2-dimethoxy-2phenylacetophenone (DMPA) as photoinitiator (PI). The resulting prepolymers were then photocrosslinked under UV irradiation to form the networks. The effect of varying UV curing time and DMPA content on chemical, structural, mechanical, and wettability properties of POSCI were analysed.

\subsection{METHODS}

\subsection{Materials}

The bio-based polyester was synthesized from itaconic acid ( $\geq 99 \%$ ) (IA), succinic acid (99\%) (SA), citric acid (CA) and 1,8-octanediol (OD), with 2,2-Dimethoxy-2phenylacetophenone (99\%) (DMPA) as PI. Tetrahydrofuran (THF) was 
purchased from EMSURE. The chemicals consumed were purchased from Sigma-Aldrich (St. Louis, Missouri, US) and were directly used as received.

\subsection{Synthesis of POSCI}

POSCI prepolymer was synthesised through polycondensation by melt blending IA, SA, CA and OD in mol ratio of $5: 3: 2: 10$ at $160{ }^{\circ} \mathrm{C}$. $0.1 \mathrm{wt} \%$ DMPA was then added to the reactant mixture after 45 minutes and the stirring process was continued for another 15 minutes. The POSCI prepolymer obtained was then poured into a Teflon mould and cured under UV irradiation for $15,30,45$, and 60 minutes. The process was repeated with 1.0, and 10.0 wt $\%$ of DMPA. Hence, the polymer produced is addressed as POSCI- $x / y$ where $x$ and $y$ indicates the DMPA content and UV exposure time in minutes respectively.

\subsection{Characterization and Testing}

\subsubsection{Fourier Transform Infrared (FTIR) Spectroscopy}

Fourier-transform infrared (FTIR) spectroscopy (Nicolet iS-5-IR Sppectrometer, Thermo Fisher Scientific, US) was conducted at room temperature in an attenuated total reflectance (ATR) mode. The data was recorded with 32 number of scans and resolution of $4 \mathrm{~cm}^{-1}$ within frequency range of $4000-500 \mathrm{~cm}^{-1}$.

\subsubsection{Sol-Gel Analysis}

Sol-gel analysis was conducted to study the degree of crosslinking of the polymer. Samples $\left(1 \times 1 \mathrm{~cm}^{2}, \mathrm{n}=3\right)$ were immersed in tetrahydrofuran (THF) for $24 \mathrm{~h}$ followed by drying in vacuum oven at $55{ }^{\circ} \mathrm{C}$ for another $24 \mathrm{~h}$. The gel content and swelling ratio were calculated using the following equations:

Gel content $=\left(\frac{W_{d}}{W_{o}}\right) \times 100$

Swelling rate $=\left[\frac{\left(W_{S}-W_{d}\right)}{W_{d}}\right] \times 100$

where $W_{\mathrm{o}}$ is the original weight of the sample, $W_{\mathrm{s}}$ is the weight of the sample after swelling in THF, and $W_{\mathrm{d}}$ is the dry weight of the sample.

\subsubsection{Wettability Test}

Contact angle measurement was performed to evaluate the wettability of the polymer surfaces using VCA Optima Contact Angle System (AST PRODUCTS, INC.). The test was conducted using sessile drop method with distilled water. The measurement was obtained in triplicates and the data were presented in mean \pm standard deviation.

\subsubsection{Tensile Test}

The tensile test was conducted using Brookfield CT3 Texture Analyzer with a test speed of $0.2 \mathrm{~mm} / \mathrm{s}$ and $1 \mathrm{~N}$ load cell. The UV cured polyester samples were cut in rectangular strips $(7 \times 1 \times$ $0.6 \mathrm{~cm})$. The samples were pulled until fail. The maximum stress observed was recorded as the ultimate tensile strength while the Young's modulus was obtained from the gradient of the stressstrain curve. The test was conducted in triplicate and the data were presented in mean \pm standard deviation.

\subsection{RESULTS AND DISCUSSION}

\subsection{Chemical and Structural Properties of POSCI}

POSCI prepolymer was successfully synthesised through a catalyst-free 
polycondensation

process.

Subsequently, exposure under UV irradiation produced photocrosslinked POSCI polyester. Figure 1 summarizes the synthesis process.

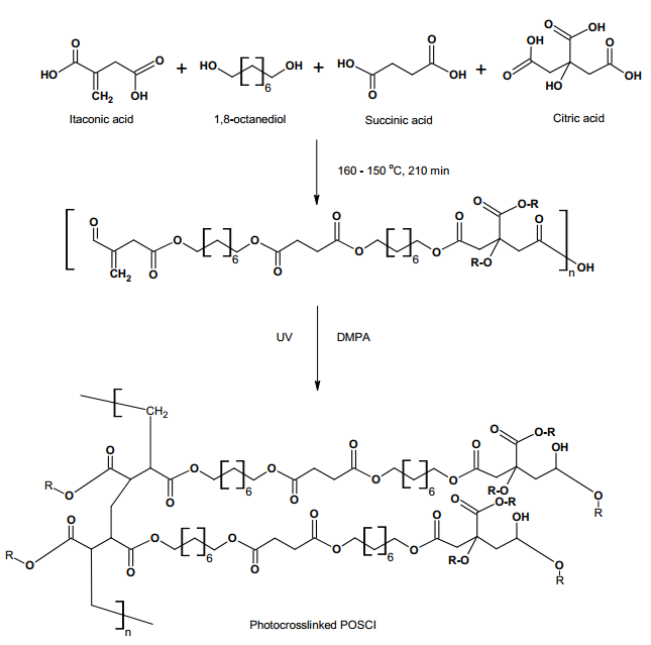

Figure 1 Synthesis process of POSCI

FTIR spectra of POSCI are presented in Figure 2. The absorption band centred at $3471.49 \mathrm{~cm}^{-1}$ observed is assigned to the $O-H$ stretching vibration of the carboxylic acids. The strong absorption peak at $1733.69 \mathrm{~cm}^{-1}$ corresponded to the $C=O$ stretching of the ester units and the second highest peak at $1166.06 \mathrm{~cm}^{-1}$ is attributed to the $\mathrm{C}-\mathrm{O}$ stretching vibration which confirms the formation of ester bonds resulting from the polycondensation process [7]. This observation applies to all spectra as UV exposure does not affects formation of ester bonds. Stretching vibration present at 2938.75 $\mathrm{cm}^{-1}$, and $2860.74 \mathrm{~cm}^{-1}$, corresponds to $-\mathrm{CH}$ bonds [8]. In Figure 2(a), the intensity of the peaks at $886.86 \mathrm{~cm}^{-1}$ and $729.81 \mathrm{~cm}^{-1}$ which indicates the presence of $\mathrm{C}=\mathrm{C}$ bond attributed to the vinyl group of the itaconic acid, appears to reduce relatively with increased UV exposure time because the double bonds are opened upon free radical polymerisation forming crosslinks [8].
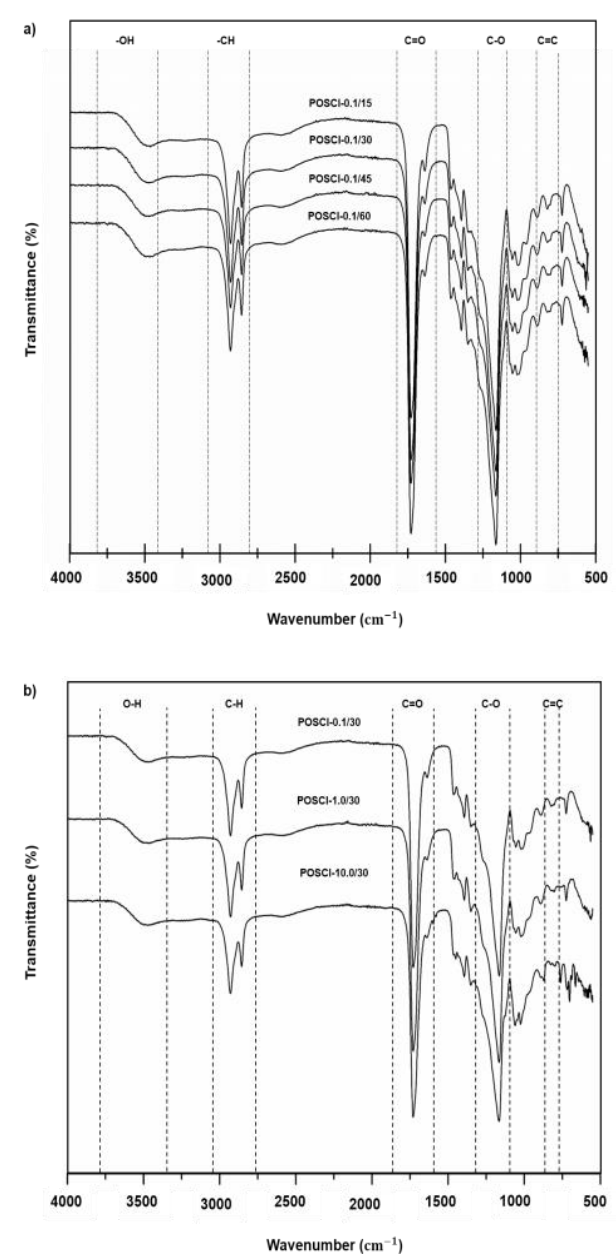

Figure 2 FTIR spectra of a) POSCI$0.1 / 15$, POSCI-0.1/30, POSCI-0.1/45, POSCI-0.1/60, b) POSCI-0.1/30, POSCI1.0/30, POSCI-10.0/30

\subsection{Sol-Gel Analysis}

Figure 3 presents the sol-gel analysis of POSCI. The highest gel fraction was $69.72 \pm 3.49 \%$ for POSCI-0.1/60 while the lowest gel fraction was $48.8 \pm 0.88$ $\%$. for POSCI-0.1/15. On the other hand, the highest swelling ratio was $264.42 \pm 5.96 \%$ for POSCI-0.1/15 and the lowest value was $115.77 \pm 2.39 \%$. for POSCI-0.1/60. This results supports the hypothesis that longer UV exposure time shall increase degree of crosslinking of the polyester. 
Both the gel fraction and the swelling ratio analysis were done to study the crosslinking properties of the synthesized photocurable biobased polyesters. They are inter-related. The smallest swelling ratio and the highest gel fraction for increasing UV curing time.
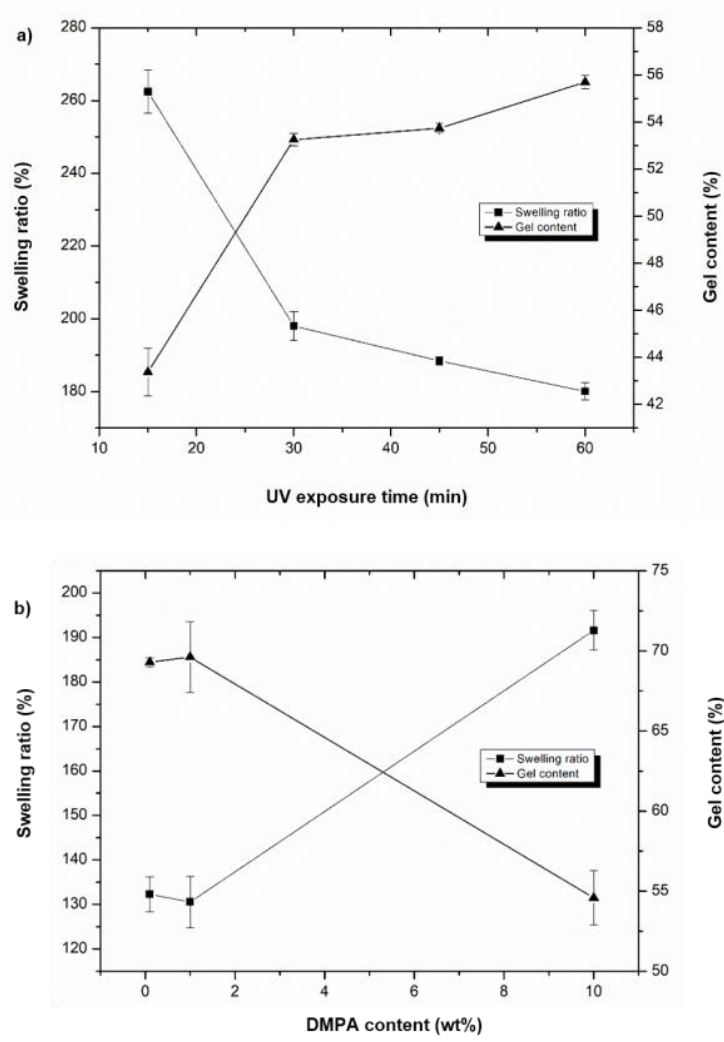

Figure 3 Sol-gel analysis of POSCI a) gel fraction, $b$ )swelling ratio of POSCI- $x / y$, as the DMPA content and UV exposure time were varied

From Figure 3, the gel content increases slightly when the DMPA content was increased by 10 fold from $0.1 \mathrm{wt} \%$ to $1.0 \mathrm{wt} \%$. However, a dramatic decrease in gel content and increase in swelling ratio can be observed when the DMPA content was increased by another 10 fold to $10 \mathrm{wt} \%$. This indicates that access DMPA is a limiting factor to free radical polymerisation of the alkyl group of the itaconic acid.

\subsection{Contact Angle Analysis}

The contact angle of POSCI increases correspondingly to the increased UV exposure time as presented in Table 1. The lowest value was $45.57 \pm 7.97$ while the highest value was $70.73 \pm$ 6.01. From the results it is clear that all the synthesized polyesters were hydrophilic as they have contact angle less than $90^{\circ}$ [9].

Table 1 Average Contact angle of POSCI

\begin{tabular}{cc}
\hline Sample & $\begin{array}{c}\text { Average } \\
\text { contact angle }\left({ }^{\circ}\right)\end{array}$ \\
\hline POSCI-0.1/15 & $45.57 \pm 7.97$ \\
POSCI-0.1/30 & $51.73 \pm 5.60$ \\
POSCI-0.1/45 & $64.03 \pm 5.80$ \\
POSCI-0.1/60 & $70.73 \pm 6.01$ \\
POSCI-1.0/30 & $60.07 \pm 4.92$ \\
POSCI-10.0/30 & $76.9 \pm 4.81$ \\
\hline
\end{tabular}

This indicates that, increase in UV curing time increase the contact angle of the synthesized polyester in which the polymers become more hydrophobic. This is because increased in UV curing time will increase the cross link density of the polymer [10]. The more crosslink between the polymers cause the polymer to be less hydrophilic. Similarly, the contact angle increases from $(51.73 \pm 5.60)^{\circ}$ to $(76.90 \pm 4.81)^{\circ}$ as the DMPA content increases from 0.1 to $10.0 \mathrm{wt} \%$. This indicates that the hydropholicity of POSCI decreases with increased DMPA content. This is attributed to the increase in hydrophobic component present as the DMPA has a nonpolar nature. 


\subsection{Tensile Test}

Table 2 presents the mechanical properties of POSCI-0.1/30, POSCI$0.1 / 60$, POSCI-1.0/30, and, POSCI$10.0 / 30$ of $0.6 \mathrm{~cm}$ thickness. Apparently, POSCI-0.1/60 exhibits improved mechanical properties compared to POSCI-0.1/30 with higher ultimate tensile strength (UTS), elongation at break and Young's modulus. This is contributed by the higher crosslinking degree occur between the polyester chains. Thus, higher strength is needed to break the polymer bonding.

The ultimate tensile strength (UTS) of POSCI increases significantly from $31.84 \pm 5.65 \mathrm{kPA}$ to $55.39 \pm 6.31 \mathrm{kPa}$ as the DMPA content increases from 0.1 to $1.0 \mathrm{wt} \%$. However, the UTS declines to $34.54 \pm 2.58 \mathrm{kPa}$ when the DMPA content increases to $10.0 \mathrm{wt} \%$. This indicates that POSCI-10 had lower mechanical strength corresponding to lowered crosslinking degree as suggested by the sol-gel result.

Table 2 Mechanical properties of POSCI

\begin{tabular}{cccc}
\hline Sample & $\begin{array}{c}\text { Ultimate Tensile } \\
\text { Strength } \\
(\mathbf{k P a})\end{array}$ & $\begin{array}{c}\text { Elongation at Break } \\
(\mathbf{\%})\end{array}$ & $\begin{array}{c}\text { Young's Modulus } \\
\mathbf{( k P a )}\end{array}$ \\
\hline POSCI-0.1/30 & $31.84 \pm 5.65$ & $8.55 \pm 1.92$ & $4.27 \pm 0.13$ \\
POSCI-0.1/60 & $56.7 \mathrm{I} \pm 13.1$ & $9.97 \pm 2.85$ & $7.703 \pm 0.51$ \\
POSCI-1.0/30 & $55.39 \pm 6.31$ & $15.72 \pm 0.50$ & $3.92 \pm 0.05$ \\
POSCI-10/30 & $34.54 \pm 2.58$ & $15.97 \pm 2.71$ & $2.40 \pm 0.03$ \\
\hline
\end{tabular}

\subsection{CONCLUSION}

A novel biobased photocrosslinked polyester membrane was synthesized succcessfully. This study has demonstrated that UV exposure time and DMPA content are parameters that can be used to manipulate structural, wettability, and mechanical properties of POSCI. The FTIR results prove the formation of ester bond in the synthesized polyesters. Sol-gel analysis confirms that increasing UV exposure time increases the crosslinking degree of POSCI while excess DMPA content can be a limiting factor. Consistently, the mechanical properties of POSCI were also improved with increased UV exposure time. All the synthesized polyesters exhibited hydrophilic properties although the wettability decreases with increased UV exposure time and DMPA content.

\section{ACKNOWLEDGEMENT}

The authors would like to thank Universiti Teknologi Malaysia for the financial support provided through the Research University Grant (Ref no. PY/2017/00481) and Higher Institution Centre of Excellence (HICoE) grant (PY/2016/07781).

\section{REFERENCES}

[1] J. Dai, S. Ma, X. Liu, L. Han, Y. $\mathrm{Wu}$, et al. 2015. Synthesis of BioBased Unsaturated Polyester Resins and Their Application in Waterborne Uv-Curable Coatings. Prog. Org. Coat. 78: 49-54.

[2] I. Bechthold, K. Bretz, S. Kabasci, R. Kopitzky, And A. Springer. 2008. Succinic Acid: A New Platform Chemical for Biobased Polymers from 
Renewable Resources. Chem. Eng. Tech. 31: 647-654.

[3] R. Wang, J. Zhang, H. Kang, and L. Zhang. 2016. Design, Preparation and Properties of Bio-Based Elastomer Composites Aiming at Engineering Applications. Comp. Sci. Tech. 133: 136-156.

[4] A. L. Holmberg, K. H. Reno, R. P. Wool, and I. Epps, Thomas. 2014. Biobased Building Blocks for the Rational Design of Renewable Block Polymers. Soft Matter. 10: 7405-7424.

[5] R. Wool and X. S. Sun. 2011. BioBased Polymers and Composites. Elsevier Science.

[6] H. Tham Weng, U. Wahit Mat, R. Abdul Kadir Mohammed, W. Wong Tuck, and O. Hassan. $2016 . \quad$ Polyol-based Biodegradable Polyesters: A Short Review. Rev. Chem. Eng. 201.

[7] D. Garlotta. 2001. A Literature Review of Poly (Lactic Acid). Journal of Polymers and the Environment. 9(2): 63-84.

[8] M. Hartmann. 1998. High Molecular Weight Polylactic Acid Polymers. Biopolymers From Renewable Resources. Springer. 367-411.

[9] A.-C. Albertsson And I. K. Varma. 2003. Recent Developments in Ring Opening Polymerization of Lactones for Biomedical Applications. Biomacromolecules. 4(6): 14661486.

[10] K. M. Zia, A. Noreen, M. Zuber, S. Tabasum, and M. Mujahid. 2016. Recent Developments and Future Prospects on Bio-based Polyesters Derived From Renewable Resources: A Review. Int. J. Biol. Macromol. 82: 10281040 .
[11] B. Amsden. 2007. Curable, Biodegradable Elastomers: Emerging Biomaterials for Drug Delivery and Tissue Engineering. Soft Matter. 3(11): 1335-1348.

[12] Y. Wang, Y. M. Kim, and R. Langer. 2003. In Vivo Degradation Characteristics of Poly(Glycerol Sebacate). $J$. Biomed. Mater. Res. A. 66A(1): 192-197.

[13] D. G. Barrett, T. J. Merkel, J. C. Luft, and M. N. Yousaf, 2010. One-step Syntheses of Photocurable Polyesters Based on a Renewable Resource. Macromolecules. 43(23): 96609667.

[14] Y. Wang, G. A. Ameer, B. J. Sheppard, and R. Langer. 2002. A Tough Biodegradable Elastomer. Nat. Biotechnol. 20: 602.

[15] J. Yang, A. R. Webb, and G. A. Ameer. 2004. Novel Citric Acidbased Biodegradable Elastomers for Tissue Engineering. Adv. Mater. 16(6): 511-516.

[16] J. M. Halpern, R. Urbanski, A. K. Weinstock, D. F. Iwig, R. T. Mathers, et al. 2014. A Biodegradable Thermoset Polymer Made by Esterification of Citric Acid and Glycerol. $J$. Biomed. Mater. Res. A. 102(5): 1467-1477.

[17] B. G. Amsden, G. Misra, F. Gu, and H. M. Younes. 2004. Synthesis and Characterization of a Photo-Cross-Linked Biodegradable Elastomer. Biomacromolecules. 5(6): 2479-2486.

[18] L. Huang, R. Jiang, J. Wu, J. Song, H. Bai, et al. 2017. Ultrafast Digital Printing Toward 4d Shape Changing 
Materials. $A d v$. Materials. 29(7): 1605390-N/A.

[20] S. H. Lee, R. You, Y. I. Yoon, C. L. Nijst, J. P. Bruggeman, J. M. Karp, L. Ferreira, A. Zumbuehl, et al. 2007. Synthesis and Characterization of Photocurable Elastomers From Poly (Glycerol-CoSebacate). Biomacromolecules. and W. H. Park. 2017. Preparation and Characterization of Acrylic Pressure-Sensitive Adhesives Based on Uv and Heat Curing Systems. Int. J. Adhes. Adhes. 75: 190-195.

8(10): 3067-307 